\title{
26
}

\section{Evaluation strategy for ITEM quality}

\author{
C.D. O'Mahony, P. Wild, I.D. Selwood, L. Kraidej, and M.G. \\ Reyes
}

\begin{abstract}
To produce a quality ITEM system, the essential process of evaluation must not be ignored. Within an existing framework, this paper discusses how we should evaluate ITEM systems and considers what objective and subjective measures are possible. Instruments are proposed for evaluating both individual school systems and systems used by groups of schools. The paper concludes with recommendations for future ITEM research.
\end{abstract}

\section{Keywords}

Educational management, evaluation, methodologies, future developments.

\section{INTRODUCTION}

Around the globe, those responsible for education delivery, be they government agencies or private foundations, are seeking ways to maximise their effectiveness, as measured against both external and internal criteria. In schools, an era of economic rationalism has dictated that educational managers must do 'more with less', and school decision-makers are more than ever calling for ways to measure and evaluate both curriculum and administrative programmes.

In any field of endeavour, future performance can be improved by learning from experience. The process of learning is more effective if it is properly organised rather than being haphazard and left to chance. Panic learning of lessons resulting from a painful and public disaster is insufficient (CCTA, 1994). In this context, evaluating the quality and effectiveness of IT systems for educational management is of great importance. As schools make greater investments in their IT/IS portfolios, evaluating the quality of this function has become a major concern. Evaluation assists to inform designers, programmers, installers, trainers and support teams so that barriers to system use are removed and promoters are used to encourage system use (Wild \& Fung, 1996).

Tools for performing such evaluations are, however, not easily found or generated. Commenting on ITEM in seven nations, Visscher (1991) has noted:

"None of the countries has studied in a systematic way the quality of the available information systems. This is a universal problem; in fact, very little empirical data on system quality are available. ... 
This is regrettable since insight into variables that determine system quality can help to build better systems."

During the 1996 International Conference on ITEM for the Schools of the Future, ITEM evaluation was identified as a major theme for discussion. In particular, discussion addressed the following questions:

- How should we evaluate the quality of IT systems for educational management?

- What problems have been identified?

- What objective measures are possible?

What subjective issues are relevant?

Each of these questions requires further decomposition. During the Conference, discussions built on the focus questions, and this paper encapsulates the concrete proposals and recommendations presented to the Working Conference in the closing session. The following pages develop the focus questions in further detail, highlighting some of the issues relevant to the evaluation of ITEM.

\section{HOW SHOULD WE EVALUATE THE QUALITY OF ITEM SYSTEMS?}

The development of appropriate evaluation measures is still pre-scientific. The intrinsically qualitative nature of such measures requires agreement on clear and concise terms of reference. One strategy for developing appropriate evaluation measures is offered by Fitzgerald (1993), as follows:

1. Identify / validate determinants of success;

2. Identify / validate the dimensions of ITEM that influence their success;

3. Devise measurement instruments for each of the constructs identified in steps 1 and 2;

4. Link each of these constructs with its operational indicators;

5. Select appropriate methodologies for data collection and analysis.

Members of the Discussion group used this strategy to frame and stimulate debate.

The Discussion Group believed that constructive and useful evaluation must be guided by an underlying framework. To this end, previous research by DeLone \& McLean (1992) was considered appropriate in providing a model of ITEM success (Figure 1).

This model proposes a framework of six variables which lead to success with information systems. These variables are System Quality, Information Quality, Use, User Satisfaction, Individual Impact and Organisational Impact. However, each of these 'variables' hides a complex interconnection and interweaving of influencing factors. The DeLone \& McLean framework, originally developed as a taxonomy of research reports, has received informal support from the information systems research community. Such an underlying framework parallels the first point of the strategy suggested by Fitzgerald (1993).

\section{WHAT PROBLEMS HAVE BEEN IDENTIFIED?}

The experiences and observations of group participants assisted in developing this theme. Problems were perceived both with IT in Educational Management, and with evaluations themselves. 


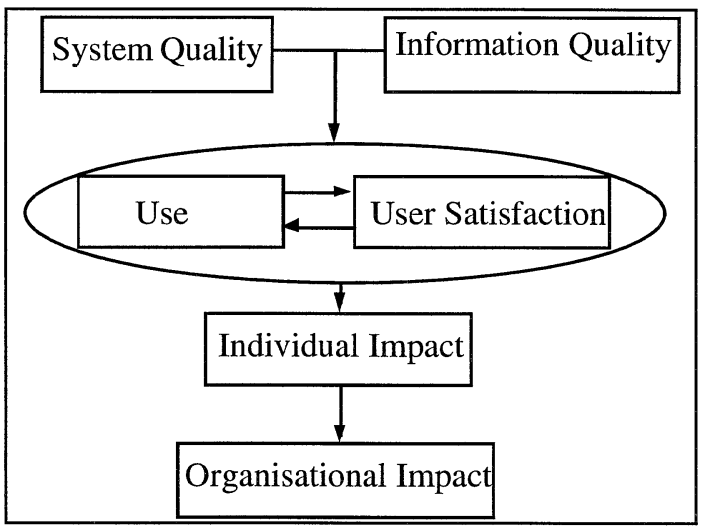

Figure 1 IS success model (DeLone \& McLean 1992).

Problems with ITEM include use and usability, staff training, staff awareness and resistance to change. These issues, and others less predictable, were identified in a small scale research project which aimed at contextualising industrial based evaluation tools for the education sector (Wild et al., 1992). Rapidly increasing information needs have meant that systems have been developed reactively rather than proactively to improve organisational efficiency and effectiveness (Wild \& Fung, 1996). Another issue explored at the conference was the influence of organisational culture on ITEM effectiveness (O’Mahony, 1996; Reyes 1996).

Problems with evaluations themselves include such issues as agreement on criteria, agreement on quantitative and qualitative methods, and the politicising of the evaluation process (Hirschheim \& Smithson, 1987). The Discussion Group noted that evaluation often became a low priority in ITEM development and maintenance efforts, and recognised that useful evaluations must be continuous and cyclical in nature Wild \& Fung, 1996). The evaluation process must necessarily be time-consuming, but is crucial to achieving success throughout many parts of educational organisations. Formal feedback mechanisms are required, which are user-focussed, throughout ITEM development as well as at all levels of use.

\section{WHAT OBJECTIVE MEASURES ARE POSSIBLE? WHAT SUBJECTIVE ISSUES ARE RELEVANT?}

Both the ITEM literature and mainstream information system literature bemoan the lack of appropriate objective, quantitative methods for evaluating IS quality (O'Mahony, 1995; Visscher, 1991). Quantitative approaches include measurement of IS in terms of return on investment (Willcocks, 1994), but this has limited application in a schools context.

Objective measures worthy of further exploration include Critical Success Factors and Benchmarking (Rolstadas, 1995). The use of educational outcomes to justify ITEM investment 
Table 1 Dimensions of success variables

\begin{tabular}{|c|c|c|}
\hline Variable & Quantitative Measures & Qualitative Measures \\
\hline System Quality & $\begin{array}{l}\text { Cost } \\
\text { Speed } \\
\text { Capacity } \\
\text { Robustness, reliability, consistency } \\
\text { Mean time between failures } \\
\text { Upgradability } \\
\text { Security, control } \\
\text { Validation, verification } \\
\text { Support (training \& technical) } \\
\text { Compatibility }\end{array}$ & $\begin{array}{l}\text { Flexibility, function } \\
\text { User Friendliness } \\
\text { Maintainability } \\
\text { Documentation (User, task, technical) }\end{array}$ \\
\hline $\begin{array}{l}\text { Information } \\
\text { Quality }\end{array}$ & Compatibility & $\begin{array}{l}\text { Accuracy } \\
\text { Relevance } \\
\text { Recency } \\
\text { Completeness }\end{array}$ \\
\hline Use & $\begin{array}{l}\text { Keying, error handling, navigation, } \\
\text { output } \\
\text { Utilisation } \\
\text { Frequency of use }\end{array}$ & Avoidance of use \\
\hline $\begin{array}{l}\text { User } \\
\text { Satisfaction }\end{array}$ & Stress & $\begin{array}{l}\text { Stress } \\
\text { Ease of use } \\
\text { Task match } \\
\text { Support } \\
\text { Perceived consequences of use / } \\
\text { removal of use } \\
\text { Task variety } \\
\text { Empowerment / influence }\end{array}$ \\
\hline $\begin{array}{l}\text { Individual } \\
\text { Impact }\end{array}$ & $\begin{array}{l}\text { Productivity } \\
\text { Working environment (EEC directive } \\
\text { 90/270/1992) } \\
\text { Reskilling, competence } \\
\text { Attendance }\end{array}$ & $\begin{array}{l}\text { Productivity } \\
\text { Working environment } \\
\text { Motivation } \\
\text { Job descriptions }\end{array}$ \\
\hline $\begin{array}{l}\text { Organisational } \\
\text { Impact }\end{array}$ & $\begin{array}{l}\text { Staff turnover } \\
\text { Marketing effectiveness } \\
\text { Accounting flexibility } \\
\text { Cost benefit analysis } \\
\text { EDUCATIONAL OUTCOMES }\end{array}$ & $\begin{array}{l}\text { Management culture } \\
\text { Management practices (eg } \\
\text { Communication, Control, Command) } \\
\text { Accountability } \\
\text { Responsibility } \\
\text { Quality of decision making } \\
\text { EDUCATIONAL OUTCOMES }\end{array}$ \\
\hline
\end{tabular}

has so far not been validated. Inter-school, inter-system and inter-national comparisons may well assist in the development of objective measures.

Subjective measures are also highly relevant. The influence of soft systems methodologies on qualitative research is a growing trend. Work by such researchers as Sauer (1993) has offered alternatives for IS evaluation. The concept of information systems failure is a valuable insight into the importance of ITEM evaluation. Variables identified by Visscher (1991) in the development of computer assisted school administration (CASA) show a marked similarity with the DeLone \& McLean framework. They are Design \& Development Strategy, IS Quality, Other Factors That Affect Use, Use of IS and Impact. Relationships between these components are still subject to debate among ITEM researchers.

Although useful for individual schools, the key value of subjective measures is ultimately their generalisability.

Using DeLone \& McLean's model of IS success, the discussion group identified the measures shown in the following table (Table 1). The identification of these measures parallels the second point in the strategy suggested by Fitzgerald (1993). 
It should be noted that the dimensions identified in Table 1 are not intended to be exhaustive. Many constructs can and should be decomposed. For instance, 'individual impact' varies depending on the individual's position within the school. Some stakeholders use ITEM in an administrative mode, whereas others utilise ITEM in a management mode.

\section{MEASUREMENT INSTRUMENTS}

One instrument that incorporates many of the above constructs is the User Acceptability Audit (Wild et al, 1992). Originally developed by Richardson (1987), the User Acceptability Audit has already been successfully trialled in UK schools. Within an individual school it represents a qualitative measurement instrument. Across groups of schools, however, the User Acceptability Audit becomes a powerful instrument for collecting data which can then be analysed in a more quantitative way.

Instruments for measuring qualitative variables include the following:

- Questionnaire

- Logged data collection

- Structured interview

Action research methodologies also show potential for gathering rich qualitative data on ITEM. Despite overlap between instruments, each appears to make a unique contribution to the evaluation process. A multi-method strategy will yield more reliable data (Henderson et al 1995).

\section{CONCLUSION}

The evaluation of ITEM is clearly an issue that requires further investigation. In many ITEM development projects evaluation is performed ad hoc, and results from evaluations are frequently ignored in project reviews. The authors have proposed the use of an existing framework for the identification of appropriate evaluation variables. This framework considers ITEM evaluation from six different perspectives, making use of both objective and subjective measures.

Appropriate methodologies for data collection have been proposed in this paper. The development of rigorous measurement instruments for each of these constructs should be the subject of future research. Only through the development of valid evaluation techniques will ITEM projects achieve success.

\section{REFERENCES}

CCTA (1994) PRINCE project evaluation. London: HMSO.

DeLone, W.H., and McLean, E.R. (1992) Information systems success: the quest for the dependent variable. Information Systems Research, 3(1), 60-95.

Fitzgerald, E. (1993) Success measures for IS strategic planning. Journal of Strategic Information Systems, 2(4), 335-350.

Henderson, R., Podd, J., Smith, M. and Varela-Alvarez, H. (1995) An examination of four user-based software evaluation methods. Interacting with Computers, 7(4), 412-432. 
Hirschheim, R. and Smithson, S. (1987) Information systems evaluation: myth and reality, in Information Analysis: selected readings (ed. R.D. Galliers). AddisonWesley, Wokingham, UK.

O'Mahony, C.D. (1995) Improving school information systems management: the quest for quality. Australian Catholic University, Sydney.

O'Mahony, C.D. \& Dampney, C.N.G. (1995) Trends in the management of school information systems, in Proceedings: 6th Australasian Conference on Information Systems, Sept 1995, Curtin University, Perth, W. Australia.

O'Mahony, C.D. (1996) IS effectiveness and organisational culture: an underlying model for ITEM evaluation, in Proceedings of the 2nd IFIP International Working Conference on ITEM, July 1996, Hong Kong Bapist University, Hong Kong.

Reyes, M.G. (1996) The impact of organisational culture on success of information projects, in Proceedings of the 2nd IFIP International Working Conference on ITEM, July 1996, Hong Kong Bapist University, Hong Kong.

Richardson, S. (1987) Operationalising usability and acceptability: a methodological review, in New methods in applied ergonomics (eds. J.R. Wilson et al.), Taylor \& Francis, London.

Rolstadas, A. (1995) Benchmarking: theory and practice. Chapman \& Hall, London.

Sauer, C. (1993) Why information systems fail: a case study approach. Alfred Waller, Henley-on-Thames.

Selwood, I.D. (1995) The development of ITEM in England and Wales, in (1995) Information technology in educational management (eds. B.Z. Barta et al.), Chapman \& Hall, London.

Visscher, A.J. (1991) Computer assisted school administration and management: the state of the art in seven nations." Journal of Research on Computing in Education, 24(1), 146-168.

Wild, P. \& Fung, A.C.W. (1996) Evaluation of ITEM for proactive development, in Proceedings of the 2nd IFIP International Working Conference on ITEM, July 1996, Hong Kong Bapist University, Hong Kong.

Wild, P., Scivier, J. and Richardson, S. (1992) An Evaluation of a LEA's Secondary Schools IT system for LMS Support. Education Management and Administration, 20(4), 40-48.

Willcocks, L. (1994) Information management: the evaluation of information systems investments. Chapman and Hall, London. 